\title{
Parents' Marital Status and Child Physical Abuse Potential: The Mediation of Depression Symptoms
}

\author{
Diogo Lamela ${ }^{1}{ }^{1} \cdot$ Bárbara Figueiredo $^{2}$
}

(C) Springer Science+Business Media New York 2016

\begin{abstract}
Informed by a social interactional framework of stress and parenting, the aim of this study was to examine the mediating effect of depression symptoms on the association between parents' marital status (married and divorced parents) and child physical abuse potential, in a Portuguese community sample. It was hypothesized that the possible observed differences between divorced and married parents in the child physical abuse potential would be explained by their depression symptoms. Parents $(N=892)$ were assessed in their marital status, severity of depression symptoms and child physical abuse potential. Results showed that, when compared with married parents, divorced parents had higher child physical abuse potential. However, parents' depression symptomatology was found as a mediator of the effect of marital status differences on child physical abuse potential. The influence of the status of divorced parents on the increase of child physical abuse potential was explained by the increase of the parents' depression symptoms. This finding suggested that parents' divorced status had no longer an effect on child physical abuse potential when parents' depression symptomatology was tested as a mediator variable. The present mediation model explained $47 \%$ of the variability in the child physical abuse potential score. Practical implications of these findings for prevention and psychological intervention are also discussed.
\end{abstract}

Diogo Lamela

lamela@ulp.pt

1 School of Psychology, Education \& Sports, Lusófona University of Porto, 4000-098 Porto, Portugal

2 School of Psychology, University of Minho, Braga, Portugal
Keywords Child physical abuse potential $\cdot$ Child physical abuse $\cdot$ Marital status $\cdot$ Divorce $\cdot$ Depression symptoms $\cdot$ Mediation

\section{Introduction}

Divorce is one of the most stressful experiences during adulthood (Lillberg et al. 2003; Middeldorp et al. 2008). From a developmental perspective, divorce challenges individuals to accomplish some demanding developmental tasks elicited by marital dissolution, including to proceed to emotional and psychological detachment from the exspouse, to develop an independent identity, to guarantee their financial autonomy, to reorganize their social networks, to manage the legal aspects of divorce, and, for divorced parents, to create a post-divorce cooperative coparenting relationship with the ex-spouse (Clarke-Stewart and Brentano 2006; Hetherington and Kelly 2002). A large body of literature has consistently demonstrated that this demanding developmental process may have a detrimental impact on the subjective well-being and mental health of divorced adults (Afifi et al. 2006; Breslau et al. 2011; Mancini et al. 2011). Despite some interindividual variability in the severity and duration of divorce-related negative outcomes on mental health might be expected (e.g., Lamela et al. 2014), divorced adults tended to report more psychological and physiological distress, less life satisfaction, and greater risk of suicide than married adults (Corcoran and Nagar 2010; Lucas 2005; van Eck et al. 2005; Yárnoz-Yaben et al. 2016). When compared with married individuals, divorced adults showed more physical 
health problems, more alcohol and drugs abuse, and higher risk of mortality (Lorenz et al. 2006; Sbarra et al. 2011).

Divorced adults also exhibit more psychopathological symptoms than their counterparts (Breslau et al. 2011). Some studies have demonstrated that divorce is an important risk factor for depression (Afifi et al. 2006; Bromet et al. 2011; Bulloch et al. 2009). For example, Bulloch et al. (2009) found that individuals with no depression during marriage reported an increased risk (hazard ratio of 1:3) of experiencing symptoms of major depression as a consequence of divorce. In another study, divorced mothers reported 1.8 increased odds for depression compared with married mothers (Afifi et al. 2006).

A large body of research also has documented that, when compared with married parents, divorced parents show more disruptive parenting attitudes and behaviors, including more coercive parenting practices (Sidebotham and Golding 2001), intrusive and rejecting parenting behaviors (GibsonDavis and Gassman-Pines 2010), and parenting stress (Osborne et al. 2012). Evidence from samples with different sociodemographic characteristics also suggested that divorce status is one of the most significant predictors of child physical abuse (Fuller-Thomson and Sawyer 2014; Miragoli et al. 2015; Weissman et al. 2003). Consistent with these findings, epidemiological studies indicated that the divorced parents' increased likelihood to physically abuse their children is between two and four times higher than married parents (Afifi et al. 2009; Collishaw et al. 2007).

However, the effect of parents' divorce on negative parenting behavior and on heightened risk of child physical abuse is not well established in literature (Strohschein 2007; Turner et al. 2007). More recently, in a meta-analysis of 155 studies examining risk factors of child maltreatment, Stith et al. (2009) found that single parenthood which is predominantly carried out by divorced parents was not one of the most significant predictors of child physical abuse. Instead, this meta-analytic study revealed parents' depression symptoms as one of the main predictors of child physical abuse (Stith et al. 2009). Past research had already demonstrated that parental depression strongly contributes to negative parenting, child physical abuse and poor child functioning (Lovejoy et al. 2000; Mammen et al. 2002). Depressed parents show a heightened probability to criticize and to be more hostile, angry and irritated in interactions with their children than non-depressed parents (Jaser et al. 2008). Parents' depression symptoms (e.g., sad mood, poor concentration, lack of energy, irritability, and hostility) are also associated with harsh parenting behaviors, less sensitivity to the child's developmental needs and difficulties in establishing and maintaining high levels of involvement with the child (Wilson and Durbin 2010). More specifically, when compared with non-depressed parents, depressed parents were more likely to demonstrate inconsistent discipline, to use severe physical punishment and to be physically aggressive with their children (Callender et al. 2012; Dubowitz et al. 2011).

Although past research has demonstrated that divorce and depression symptoms may be independent risk factors to child physical abuse, little is known about how both might be associated in the prediction of child physical abuse potential. Social interactional models of stress and parenting offer a conceptual framework for addressing this potential association (DeGarmo et al. 2004; Patterson and Forgatch 1990). These models analyze how acute stressors impact parental psychological functioning and parenting behaviors. More specifically, DeGarmo et al. (2004) posited that divorce challenges parents to synchronically cope with several potential stressful tasks. The severity and duration of these divorce-related tasks amplify the vulnerability for depressive symptoms during this family transition. Depression symptoms are conceptualized as an acute or chronic negative response to these developmental challenges. This model proposed that depression symptoms (including irritability, sad mood, anhedonia, and cognitive distortions) would be subsequently associated with lower perceived social support, disruptions in parents' attributions about children's behaviors and additional difficulties to positively interact with the child (DeGarmo et al. 2004; Reed et al. 2013). Over time, parenting difficulties related with depression symptoms would be also linked to a higher propensity to use ineffective parenting practices to control children's behavior, including child physical abuse (Patterson and Forgatch 1990).

Furthermore, it is well established that depression is associated with irritability, hostility, frustration, and sometimes anger (Benazzi and Akiskal 2005). In addition, irritability has been recognized as a major process variable linking parents' depression symptoms and coercive and abusive parenting behaviors (Hien et al. 2010; Shay and Knutson 2008). Drawing from these previous contributions, a plausible thesis is that parents with depression symptoms may show more difficulty in controlling adaptively their negative affect, which may be associated with more aggressive behaviors towards the child, regardless of their marital status (Medley and Sachs-Ericsson 2009). In sum, the presence and severity of depression symptoms may mediate the association between marital status and child physical abuse potential.

This possible mediating effect of depression symptoms, however, has remained unexplored at an empirical level. To address this question, the main goal of the current research was to test whether the association between marital status (married vs. divorced parents) and child physical abuse potential would be mediated by parents' depression symptoms. As divorced parents were more likely to experience more potential stressful events than married parents (Avison et al. 2007), we hypothesized that, when compared with 
married parents, parents' divorced marital status would predict child physical abuse potential. However, we also hypothesized that this association would be mediated by parents' depression symptoms. Consistent with this hypothesis, we predicted that possible observed differences between divorced and married parents in the child physical abuse potential would be explained by their depression symptoms.

\section{Method}

\section{Participants}

Parents ranged in age from 25 to 55 years. Regarding the highest level of education completed, $40.4 \%$ had 6 years of basic education, $21.3 \%$ had 9 years of basic education, 21.4 $\%$ were high school graduates, and $16.9 \%$ had completed any college degree. Regarding the professional status, $85.2 \%$ were employed, $6 \%$ were unemployed, $8.2 \%$ were at home, and $<1 \%$ reported other status (retired or student). Median family income per month of the participants fell between 1.5 and 3 national minimum wages, with $5 \%$ of the sample reporting household income below 1 national minimum wage. Ninety-two percent of the participants had Portuguese nationality, $5 \%$ born in other Portuguese speaking countries (Angola, Brazil, Cape Verde, and Mozambique), and $3 \%$ of the participants had other nationality.

Demographic data for total sample are described in Table 1. The proportion of divorced participants in the sample $(5.7 \%)$ was comparable with the proportion of divorced individuals between $25-55$ years reported by the 2001 and 2011 Portuguese National Census Statistics for the Northern Portugal region, respectively, 3.4 and $7.7 \%$ (INE 2002, 2012).

\section{Procedures}

Participants were a subset of parents in the National Representative Study of Psychosocial Context of Child Abuse and Neglect in Portugal (PCCANP). Participants were mothers and fathers of children randomly selected in five public elementary schools of Northern Portugal (for a detailed description about sample selection procedures, see Figueiredo et al. 2004). This study received ethical approval from regional educational authorities (DREN, Direcção Regional da Educação do Norte), after formal permission to conduct the research from the five schools, which were randomly selected from the national list of public schools. Subsequently, the research team explained the goals and procedures of the research to the teachers of the selected schools and asks them to collaborate in the collection of the assessment protocols. All teachers agreed to collaborate with the research team. Then, all parents were invited to participate in a meeting with teachers and research team members in order to be informed about research aims and ethic procedures. Afterwards, the teachers provided the assessment protocols and letters of consent in sealed envelopes to the children who in turn handed them to both of their parents. Mothers and fathers of the same family could participate in the study. The
Table 1 Demographics, depression symptoms and child physical abuse potential scores by marital status

\begin{tabular}{|c|c|c|c|c|c|c|c|c|c|c|}
\hline & \multicolumn{7}{|c|}{ Marital status } & \multicolumn{3}{|c|}{ Total $(N=892)$} \\
\hline & \multicolumn{3}{|c|}{$\begin{array}{l}\text { Married parents } \\
(n=836)\end{array}$} & \multicolumn{3}{|c|}{$\begin{array}{l}\text { Divorced parents } \\
(n=56)\end{array}$} & \multirow[b]{2}{*}{$p$} & \multirow[b]{2}{*}{$M$} & \multirow[b]{2}{*}{ SD } & \multirow[b]{2}{*}{$\%$} \\
\hline & $M$ & SD & $\%$ & $M$ & SD & $\%$ & & & & \\
\hline \multicolumn{11}{|l|}{ Demographics } \\
\hline \multicolumn{11}{|l|}{ Gender } \\
\hline Female & & & 52.6 & & & 71.9 & .01 & & & 53.8 \\
\hline Male & & & 47.4 & & & 28.1 & & & & 46.2 \\
\hline Age (years) & 36.9 & 5.2 & & 36.1 & 5.4 & & $n s$ & 36.8 & 5.2 & \\
\hline Education ( $\leq 9$ years) & & & 61.3 & & & 63.2 & $n s$ & & & 61.7 \\
\hline $\begin{array}{l}\text { Family income per month }(<1.5 \text { national } \\
\text { minimum wage })\end{array}$ & & & 20.9 & & & 24.1 & $n s$ & & & 21.4 \\
\hline Professional status (employed) & & & 84.9 & & & 88.5 & $n s$ & & & 85.2 \\
\hline Portuguese nationality & & & 92.7 & & & 91.1 & $n s$ & & & 91.9 \\
\hline Number of children & 1.9 & 0.7 & & 2.1 & 1.2 & & .01 & 1.8 & 0.8 & \\
\hline \multicolumn{11}{|l|}{ Self-report measures } \\
\hline Depression scale BSI & 2.7 & 3.2 & & 5.4 & 5.3 & & .001 & 2.9 & 3.4 & \\
\hline Abuse scale CAPI & 21.2 & 11.2 & & 29.1 & 15.7 & & .001 & 21.7 & 11.7 & \\
\hline
\end{tabular}

$B S I$ brief symptom inventory, $C A P I$ child abuse potential inventory 
questionnaires were sent to every parent or surrogate parent ( $N=1480)$ having at least one child attending the selected schools. The overall rate of compliance from parents (i.e., in returning the protocols in sealed envelopes to the teachers by their children) was $69 \%(N=1021)$. For current analyses, only participants without missing data were included (50 participants were excluded). No statistical differences between retained and excluded participants were found in main sociodemographic variables, such as age, $t(1019)=-.43, n s$, gender, $\chi^{2}(1)=.51, n s$, and number of children, $t(1019)=1.34, n s$. From the remaining 971 parents, only married and divorced participants were included in the present study (i.e., participants with single, widow, cohabiting marital status were excluded; $n=79$ ). The final sample comprised 892 participants, including all divorced $(n=56)$ and all married $(n=836)$ parents who provided data on all measures used in the current research. All respondents were biological or adoptive parents of the focal child.

\section{Measures}

\section{Demographic variables}

A demographic questionnaire was administered to collect participant information, including gender, age, marital status, education, and number of children. Marital status was coded as a categorical variable, married parents being coded as 1 (reference group) and divorced parents coded as 2 .

\section{Depression symptoms}

The depression scale of the Brief Symptom Inventory (BSI; Derogatis and Melisaratos 1983) was administered to assess parents' depression symptoms. Based on BSI theoretical rationale, depression symptoms are defined as experiencing depressed mood, sadness, loss of interest in life activities, unworthiness/worthlessness, hopelessness, loneliness and vulnerability to criticism. Parents responded to the 6 items of BSI depression scale based on their level of distress associated with each symptom over the previous month. The items are answered on a 5-point Likert-scale (0, not at all to 4, extremely). Past research has demonstrated the BSI depression subscale as a reliable measure for screening depression symptoms (e.g., Callender et al. 2012). The good reliability, validity, and discriminant power between community and clinical populations of the BSI was confirmed for the Portuguese translation (Canavarro 1999). Internal consistency of the Portuguese version of the BSI depression subscale was .73 (Canavarro 1999). In the current sample, Cronbach's alpha was .84 .

\section{Child physical abuse potential}

The abuse scale of the Child Abuse Potential Inventory (CAPI; Milner 1986) was used to assess parents' attitudes and practices regarding physical forms of discipline and abuse. The CAPI abuse scale examines distress, rigidity, unhappiness, problems with the child and the self, problems with the family and with others, and problems of others. The 74-item of the Portuguese version of CAPI abuse scale used in this study are answered in a forced-choice format $(0$, no or 1, yes) (Gomes 2010). Total scores on CAPI abuse scale range from 0 to 74 , with higher scores reflecting more risk of child physical abuse. The current Portuguese version of the CAPI showed very satisfactory psychometric properties $(\alpha=.92)$ and its ability to discriminate between abusive parents and community parents was supported by successfully classifying $96.2 \%$ of all cases (Gomes 2010). The internal consistency for the total score in the current sample was .90 .

\section{Data Analyses}

Firstly, $t$-tests for continuous variables and $\chi^{2}$ tests for categorical variables were conducted in order to examine differences between married and divorced parents in demographic variables, depression symptoms and child physical abuse potential. Additionally, Cohen's $d$ values were calculated to measure the effect size of the differences between the two groups. A mediational analysis was conducted to test the mediation effect of depression symptoms on the association between marital status (married/divorced) on child physical abuse potential. We used bootstrapping techniques to test mediation (Preacher and Hayes 2008; Preacher et al. 2007). Bootstrapping statistic is a nonparametric method which allows to examine the statistical significance of the cross product of paths $a$ and $b$ without assuming the normal distribution of the indirect effects (Hayes 2013). In these analyses, a mediation model is significant if the $95 \%$ bias corrected and accelerated confidence intervals $(95 \% \mathrm{CI})$ of the indirect effects do not contain zero. For the current set of analyses, a macro for SPSS created by Preacher and Hayes (2008) was employed to test our hypothesized meditational model. In the present study, parameter estimates were based on 20,000 bootstrap samples.

\section{Results}

Means, standard deviations, frequencies, and group comparison statistics for all variables are summarized in Table 1. No differences between married parents and 
divorced parents groups were found in age, $t(890)=1.31$, $n s$, education, $\chi^{2}(1)=.05, n s$, family income per month, $\chi^{2}(1)=.72, n s$, professional status, $\chi^{2}(1)=.49, n s$, and nationality $\chi^{2}(1)=.34, n s$. Differences between groups were found in gender, $\chi^{2}(1)=8.04, p<.01$. When compared with married parents, divorced parents had more children, $t(890)=-2.49, p<.01$, and reported higher scores in the BSI depression scale, $t(890)=-5.76, p<.001$, Cohen's $d=$ $-0.8(95 \% \mathrm{CI}=-1.07$ to -0.53$)$ and higher scores in the CAPI abuse scale, $t(890)=-4.95, p>.001$, Cohen's $d=$ $-0.7(95 \% \mathrm{CI}=-0.96$ to -0.41$)$.

In consequence of the significant statistical differences between married and divorced groups on gender and number of children, these two variables were entered on the mediation model as covariates. We expect that the mediation model will fit well, even with these two variables introduced as covariates.

As indicated in Fig. 1, mediation analyses revealed that when controlling the effect of parents' gender $(B=1.37$, estimated standard error $[\mathrm{SE}]=.59, n s)$ and number of children $(B=1.37, \mathrm{SE}=.39, p<.01)$, the total effect of marital status on child physical abuse potential was significant $(B=2.17, \mathrm{SE}=.52, p<.001)$. Compared with married parents (reference group), the increase of child physical abuse potential in the group of divorced parents was mediated by an increase in depression symptoms (indirect effect $=1.67 ; 95 \% \mathrm{CI}$ for bias correct indirect effect: Lower Lever $=.81$, Upper Level $=2.81$ ). The direct path from marital status to child physical abuse potential increase was not significant once depression symptoms was added to the model $(B=.51, \mathrm{SE}=.39, n s)$, meaning that the influence of the divorced status on child physical abuse potential increase was completely explained by the increase of depression symptoms. The present mediation model explained $47 \%$ of the variability in the child physical abuse potential score, $F(4,886)=193.1, p<.001$.

\section{Discussion}

Using data from a community survey carried out with Portuguese parents of school-aged children, the main goal of the current study was to test whether depression symptoms would mediate the relationship between marital status and child physical abuse potential. Previous studies have identified divorce as a statistical risk factor to child physical abuse potential (Afifi et al. 2009; Weissman et al. 2003). Some authors have argued that marriage is a protective factor against child physical abuse (Wu et al. 2004). However, little is known about how divorce may indirectly be associated with a heightened likelihood of child physical abuse. To address this limitation, the current research revealed that, when compared with married parents, divorced parents showed on average more child physical abuse potential via parental depression symptoms. Parents' divorced status had no longer an effect on child physical abuse potential when parents' depression symptomatology was tested as a mediator variable.

Taken together, the present results support conceptualizations drawn from social interactional models of stress and parenting proposing that the potential stressful nature of divorce may be detrimental to the mental health of divorced adults and cumulatively originate difficulties in parenting practices (DeGarmo et al. 2004). Our findings were also consistent with previous ones that tested separately the effect of marital status on child physical abuse (Afifi et al. 2009), the effect of marital status on parents' depression (Breslau et al. 2011), as well as the effect of depression symptoms on child physical abuse potential (Stith et al. 2009). More particularly, Lee et al. (2011) found that father's parenting stress and major depression were strongly associated with greater use of physical punishment, while Turney (2011) found that mothers' depression predicted child physical assault. However, this association did

Fig. 1 Results of the proposed mediation model.

Note: Covariates: Parents' gender and number of children. Coefficients are unstandardized parameter estimates. ${ }^{*} p<.01$; $* * p<.001$

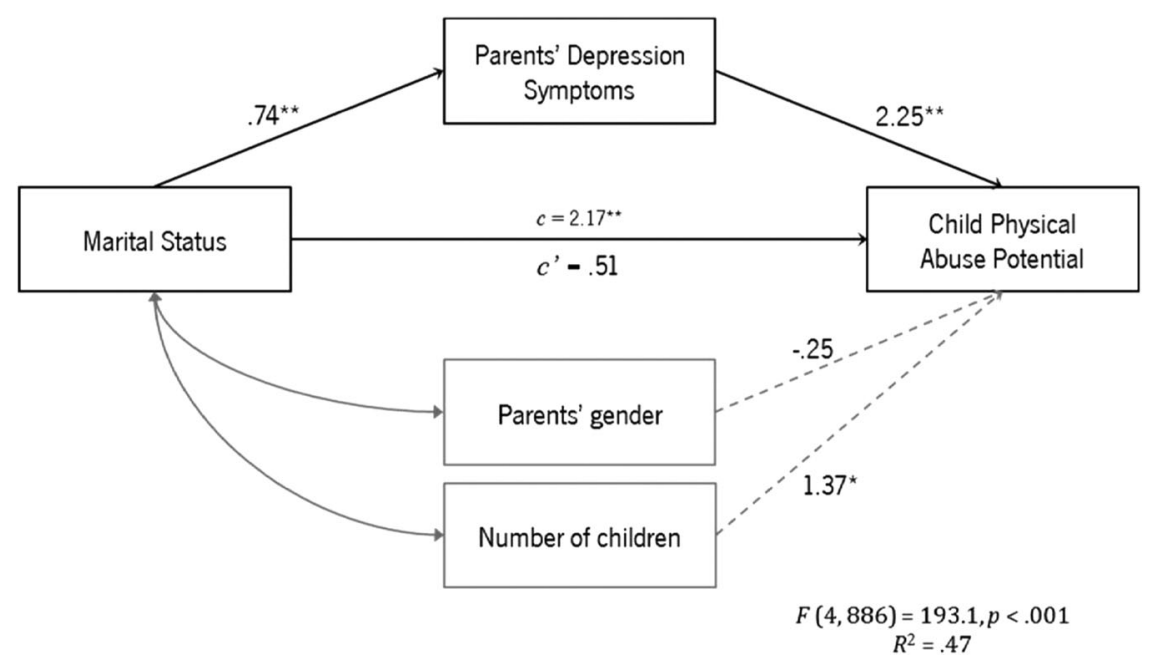


not differ along with the mother's marital status (married vs. non-married mothers), suggesting that marriage is not a significant protective factor of child physical abuse when depression is also considered as predictor.

\section{Limitations and Clinical Implications}

The results of this research should be interpreted bearing some limitations in mind. Firstly, due the cross-sectional design of the current study, our findings should not be interpreted as a causal longitudinal chain linking divorce and depression symptoms as risk factors of child abuse potential. The cross-sectional nature of the data might also inflate estimations of mediation (Maxwell and Cole 2007). Secondly, all constructs were only assessed using selfreport measures. Despite all measures used in the current research have demonstrated high and significant associations with interviewing and observational measures, multiinformant and multimethod procedures could have contributed to a higher accuracy of measurement, a decreased possible shared method variance and could also have prevented possible social desirability. Thirdly, the Portuguese version of the CAPI used in the current research did not report cut-off scores to the validity scales. In consequence, we could not detect possible distortions in the participants' CAPI responses. The exclusion of participants with elevated scores in any of the response distortion indices could increase CAPI scores reliability. As no cut scores to the response distortion indices are available to Portugal, future research should address this methodological limitation. Fourthly, marital satisfaction experienced by married parents was not assessed. Based on literature, we assumed that divorced parents had an increased risk for child physical abuse when compared with married parents. However, marriage per se may not be a protector factor for child physical abuse, since differences in child physical abuse potential may be found between parents with low marital distress and parents with high marital distress. By assessing marital distress, differences in the variability of depression symptoms between these two groups of married parents would be possible. Fifthly, information regarding time since divorce and custody status were not collected in the divorced parents group. If these variables were considered, it would be possible to test differences among divorced parents depending on their custody status and time since divorce, since literature has demonstrated that non-recent divorced or sole custody/joint custody parents report less depression symptoms, higher levels of psychological adjustment to divorce, and more positive parenting behaviors than recent divorced or non-custodial parents (Bauserman 2012; Lamela et al. 2014; Yárnoz-Yaben 2015). Finally, despite fathers and mothers of the same family could participate in the study, no question to identify both parents of the same family was included in assessment protocols. Therefore, no coding strategy could be applied to associate answers of fathers and mothers of the same family in the database. This limitation prevented us of controlling the potential dependence of observations. Despite the reports of mothers and fathers of the same family were more likely to be similar to a certain degree instead of being identical (Lee et al. 2012), the dependence of observations could lead to an underestimation of the standard errors and, by this way, contribute for a higher risk of type 1 error. However, taking into account the large sample, the bootstrapping analytic procedures, and the theoretical plausibility of the findings, the impact of the potential dependence of observations on the accuracy of the statistical results might be limited.

Our study tested depression symptoms as a mediator variable in the association between marital status and child physical abuse potential. However, depression symptoms may instead operate as a proxy risk variable for child abuse potential. A proxy risk factor is not conceptualized as causal of an outcome, but indicates the presence of a causal risk factor (Kraemer et al. 2001). Put it differently, a proxy risk variable is associated with an outcome only because it is a correlate of a strong risk factor that directly triggers the outcome. Thus, future research should test concurrently whether the association between the depression symptoms and child abuse potential may lie in other causal risk mechanisms correlated with both (e.g., emotional dysregulation, coping or attachment representations) or whether depression symptoms are in fact a strong mediator risk factor of child abuse potential as our cross-sectional findings might suggest.

Our findings have some implications for primary and secondary prevention interventions programs. Previous studies had already demonstrated that interventions that promote positive parenting are effective in preventing child physical abuse potential (Prinz et al. 2009), and in reducing future child physical abuse in abusive parents (Chaffin et al. 2004). By demonstrating that parents' depression symptoms are a proxy risk factor of child physical abuse potential, our findings suggest that interventions that aim to reduce depression symptoms may improve their effectiveness. Surprisingly, similarly to Barth's et al. (2009) conclusions, we were not able to find recently peer-review work on interventions regarding child physical abuse prevention or treatment that at the same time focus on parenting practices and parents' depression disorders, for married or divorced parents (for a review on risk factors addressed by published primary prevention programs of child physical abuse, see Klevens and Whitaker 2007).

Although not directly orientated to prevent child physical abuse potential, some published manualized programs may have clinical usefulness in reducing the risk of child 
physical abuse since they work on risk factors that intervene on child physical abuse potential (e.g., parental depression and coercive parenting practices). The Parent Management Training shows a consistent and promising efficacy in promoting positive parenting practices and reducing depression symptoms in divorced parents (DeGarmo et al. 2004; Forgatch and DeGarmo 1999). On the other hand, Keeping Families Strong (Riley et al. 2008) comprises parental education about depression, promotion of consistent and parenting practices (e.g., training of behavioral management and conflict resolution skills) and problemsolving techniques.

By promoting positive parenting practices and reducing parents' depression, these programs and other programs with similar goals may be valuable in the prevention of child physical abuse potential. However, since no effectiveness trial was conducted to test the efficacy of these programs on reducing child physical abuse potential, they should be read with caution. Overall, our findings suggested that preventive and remediate interventions on child physical abuse should include a component of parents' positive mental health promotion in their curricula.

\section{Compliance with ethical standards}

Conflict of Interest The authors declare that they have no conflict of interest.

Ethical Approval All procedures performed in studies involving human participants were in accordance with the ethical standards of the institutional and/or national research committee and with the 1964 Helsinki declaration and its later amendments or comparable ethical standards.

Informed Consent Informed consent was obtained from all individual participants included in the study.

\section{References}

Afifi, T. O., Boman, J., Fleisher, W., \& Sareen, J. (2009). The relationship between child abuse, parental divorce, and lifetime mental disorders and suicidality in a nationally representative adult sample. Child Abuse \& Neglect, 33, 139-147. doi:10.1016/ j.chiabu.2008.12.009.

Afifi, T. O., Cox, B. J., \& Enns, M. W. (2006). Mental health profiles among married, never-married, and separated/divorced mothers in a nationally representative sample. Social Psychiatry and Psychiatric Epidemiology, 41, 122-129. doi:10.1007/s00127005-0005-3.

Avison, W. R., Ali, J., \& Walters, D. (2007). Family structure, stress, and psychological distress: A demonstration of the impact of differential exposure. Journal of Health and Social Behavior, 48, 301-317. doi:10.1177/002214650704800307.

Barth, R., Semidei, J., Radel, L. F., Nolan, C., Pierce, R. L., Pierce, L. H., et al. (2009). Preventing child abuse and neglect with parent training: Evidence and opportunities. The Future of Children, 19, 95-118. doi:10.1353/foc.0.0031.
Bauserman, R. (2012). A meta-analysis of parental satisfaction, adjustment, and conflict in joint custody and sole custody following divorce. Journal of Divorce \& Remarriage, 53, 464-488. doi:10.1080/10502556.2012.682901.

Benazzi, F., \& Akiskal, H. (2005). Irritable-hostile depression: Further validation as a bipolar depressive mixed state. Journal of Affective Disorders, 84, 197-207. doi:10.1016/j.jad.2004.07.006.

Breslau, J., Miller, E., Jin, R., Sampson, N. A., Alonso, J., Andrade, L. H., et al. (2011). A multinational study of mental disorders, marriage, and divorce. Acta Psychiatrica Scandinavica, 124, 474-486. doi:10.1111/j.1600-0447.2011.01712.x.

Bromet, E., Andrade, L. H., Hwang, I., Sampson, N. A., Alonso, J., de Girolamo, G., et al. (2011). Cross-national epidemiology of DSM-IV major depressive episode. BMC Medicine, 9, 90 doi:10. 1186/1741-7015-9-90.

Bulloch, A. G., Williams, J. V., Lavorato, D. H., \& Patten, S. B. (2009). The relationship between major depression and marital disruption is bidirectional. Depression and Anxiety, 26, 1172-1177. doi:10.1002/da.20618.

Callender, K. A., Olson, S. L., Choe, D. E., \& Sameroff, A. J. (2012). The effects of parental depressive symptoms, appraisals, and physical punishment on later child externalizing behavior. Journal of Abnormal Child Psychology, 40(3), 471-483. doi:10.1007/ s10802-011-9572-9.

Canavarro, C. (1999). Inventário de sintomas psicopatológicos: BSI [The brief symptoms inventory: BSI]. In M. Simões, M. Gonçalves, \& L. Almeida (Eds.), Testes e provas psicológicas em Portugal [Psychological tests in Portugal] (pp. 95-109). Braga: APPORT.

Chaffin, M., Silovsky, J. F., Funderburk, B., Valle, L. A., Brestan, E. V., Balachova, T., et al. (2004). Parent-child interaction therapy with physically abusive parents: Efficacy for reducing future abuse reports. Journal of Consulting and Clinical Psychology, 72, 500-510. doi:10.1037/0022-006X.72.3.500.

Clarke-Stewart, A., \& Brentano, C. (2006). Divorce: Causes and consequences. London: Yale University Press.

Collishaw, S., Pickles, A., Messer, J., Rutter, M., Shearer, C., \& Maughan, B. (2007). Resilience to adult psychopathology following childhood maltreatment: Evidence from a community sample. Child Abuse \& Neglect, 31, 211-229. doi:10.1016/j. chiabu.2007.02.004.

Corcoran, P., \& Nagar, A. (2010). Suicide and marital status in Northern Ireland. Social Psychiatry and Psychiatric Epidemiology, 45, 795-800. doi:10.1007/s00127-009-0120-7.

DeGarmo, D. S., Patterson, G. R., \& Forgatch, M. S. (2004). How do outcomes in a specified parent training intervention maintain or wane over time? Prevention Science, 5, 73-89. doi:10.1023/B: PREV.0000023078.30191.e0.

Derogatis, L. R., \& Melisaratos, N. (1983). The brief symptom inventory: An introductory report. Psychological Medicine, 13, 595-605. doi:10.1017/S0033291700048017.

Dubowitz, H., Kim, J., Black, M. M., Weisbart, C., Semiatin, J., \& Magder, L. S. (2011). Identifying children at high risk for a child maltreatment report. Child Abuse \& Neglect, 35, 96-104. doi:10. 1016/j.chiabu.2010.09.003.

Figueiredo, B., Bifulco, A., Paiva, C., Maia, Â., Fernandes, E., \& Matos, R. (2004). History of childhood abuse in Portuguese parents. Child Abuse \& Neglect, 28, 669-682. doi:10.1016/j. chiabu.2003.11.021.

Forgatch, M. S., \& DeGarmo, D. S. (1999). Parenting through change: An effective prevention program for single mothers. Journal of Consulting and Clinical Psychology, 67, 711-724. doi:10.1037/ 0022-006X.67.5.711.

Fuller-Thomson, E., \& Sawyer, J. -L. (2014). Is the cluster risk model of parental adversities better than the cumulative risk model as an indicator of childhood physical abuse?: Findings from two 
representative community surveys. Child: Care, Health and Development, 40, 124-133. doi:10.1111/cch.12024.

Gibson-Davis, C. M., \& Gassman-Pines, A. (2010). Early childhood family structure and mother-child interactions: Variation by race and ethnicity. Developmental Psychology, 46, 151-164. doi:10. 1037/a0017410.

Gomes, J. (2010). Validação da versão portuguesa do child abuse potencial inventory [Validation of the Portuguese version of the child abuse potential inventory] (Unpublished master's thesis). Braga, University of Minho.

Hayes, A. (2013). Introduction to mediation, moderation, and conditional process analysis. New York, NY: Guilford. doi:978-1-60918-230-4.

Hetherington, M., \& Kelly, J. (2002). For better or for worse: Divorce reconsidered. New York, NY: W.W. Norton.

Hien, D., Cohen, L. R., Caldeira, N. A., Flom, P., \& Wasserman, G. (2010). Depression and anger as risk factors underlying the relationship between maternal substance involvement and child abuse potential. Child Abuse \& Neglect, 34, 105-113. doi:10. 1016/j.chiabu.2009.05.006.

INE. (2002). Censos 2001: Resultados definitivos-região Norte [Census 2001: Final results-Northern region]. Lisbon: Instituto Nacional de Estatística.

INE. (2012). Censos 2011: Resultados definitivos-região Norte [Census 2011: Final results—Northern region]. Lisbon: Instituto Nacional de Estatística.

Jaser, S. S., Fear, J. M., Reeslund, K. L., Champion, J. E., Reising, M. M., \& Compas, B. E. (2008). Maternal sadness and adolescents' responses to stress in offspring of mothers with and without a history of depression. Journal of Clinical Child and Adolescent Psychology, 37, 736-746. doi:10.1080/15374410802359742.

Klevens, J., \& Whitaker, D. J. (2007). Primary prevention of child physical abuse and neglect: Gaps and promising directions. Child Maltreatment, 12(4), 364-377. doi:10.1177/1077559507305995.

Kraemer, H. C., Stice, E., Kazdin, A., Offord, D., \& Kupfer, D. (2001). How do risk factors work together? Mediators, moderators, and independent, overlapping, and proxy risk factors. American Journal of Psychiatry, 158, 848-865. doi:10.1176/appi.ajp.158.6. 848.

Lamela, D., Figueiredo, B., \& Bastos, A. (2014). The Portuguese version of the psychological adjustment to separation test-part A (PAST-A): A study with recently and non-recently divorced adults. Journal of Happiness Studies, 15, 387-406. doi:10.1007/ s10902-013-9427-x.

Lee, S. J., Lansford, J. E., Pettit, G. S., Bates, J. E., \& Dodge, K. A. (2012). Parental agreement of reporting parent to child aggression using the conflict tactics scales. Child Abuse \& Neglect, 36, 510-518. doi:10.1016/j.chiabu.2012.04.005.

Lee, S. J., Perron, B. E., Taylor, C. A., \& Guterman, N. B. (2011). Paternal psychosocial characteristics and corporal punishment of their 3-year-old children. Journal of Interpersonal Violence, 26, 71-87. doi:10.1177/0886260510362888

Lillberg, K., Verkasalo, P. K., Kaprio, J., Teppo, L., Helenius, H., \& Koskenvuo, M. (2003). Stressful life events and risk of breast cancer in 10,808 women: A cohort study. American Journal of Epidemiology, 157, 415-423. doi:10.1093/aje/kwg002.

Lorenz, F. O., Wickrama, K. A., Conger, R. D., \& Elder, Jr., G. H. (2006). The short-term and decade-long effects of divorce on women's midlife health. Journal of Health and Social Behavior, 47, 111-125. doi:10.1177/002214650604700202.

Lovejoy, M. C., Graczyk, P. A., O'Hare, E., \& Neuman, G. (2000). Maternal depression and parenting behavior: A meta-analytic review. Clinical Psychology Review, 20, 561-592. doi:10.1016/ S0272-7358(98)00100-7.

Lucas, R. E. (2005). Time does not heal all wounds: A longitudinal study of reaction and adaptation to divorce. Psychological Science, 16, 945-950. doi:10.1111/j.1467-9280.2005.01642.x.
Mammen, O. K., Kolko, D. J., \& Pilkonis, P. A. (2002). Negative affect and parental aggression in child physical abuse. Child Abuse \& Neglect, 26, 407-424. doi:10.1016/S0145-2134(02) 00316-2.

Mancini, A. D., Bonanno, G. A., \& Clark, A. E. (2011). Stepping off the hedonic treadmill: Individual differences in response to major life events. Journal of Individual Differences, 32, 144-152. doi:10.1027/1614-0001/a000047.

Maxwell, S. E., \& Cole, D. A. (2007). Bias in cross-sectional analyses of longitudinal mediation. Psychological Methods, 12, 23-44. doi:10.1037/1082-989x.12.1.23.

Medley, A., \& Sachs-Ericsson, N. (2009). Predictors of parental physical abuse: The contribution of internalizing and externalizing disorders and childhood experiences of abuse. Journal of Affective Disorders, 113, 244-254. doi:10.1016/j.jad.2008.05. 020 .

Middeldorp, C. M., Cath, D. C., Beem, A. L., Willemsen, G., \& Boomsma, D. I. (2008). Life events, anxious depression and personality: A prospective and genetic study. Psychological Medicine, 38, 1557-1565. doi:10.1017/S0033291708002985.

Milner, J. (1986). The child abuse potential inventory manual. 2nd edn. DeKalb, IL: Psyctec.

Miragoli, S., Camisasca, E., \& Di Blasio, P. (2015). Validation of the child abuse potential inventory in Italy. SAGE Open, 5, 1-12. doi:10.1177/2158244015597044.

Osborne, C., Berger, L. M., \& Magnuson, K. (2012). Family structure transitions and changes in maternal resources and well-being. Demography, 49, 23-47. doi:10.1007/s13524-011-0080-x.

Patterson, G., \& Forgatch, M. (1990). Initiation and maintenance of process disrupting single-mother families. In G. Patterson (Ed.), Depression and aggression in family interaction (pp. 209-245). Hillsdale, NJ: Lawrence Erlbaum Associates, Inc.

Preacher, K. J., \& Hayes, A. F. (2008). Asymptotic and resampling strategies for assessing and comparing indirect effects in multiple mediator models. Behavior Research Methods, 40, 879-891. doi:10.3758/BRM.40.3.879.

Preacher, K. J., Rucker, D. D., \& Hayes, A. F. (2007). Addressing moderated mediation hypotheses: Theory, methods, and prescriptions. Multivariate Behavioral Research, 42, 185-227. doi:10.1080/00273170701341316.

Prinz, R. J., Sanders, M. R., Shapiro, C. J., Whitaker, D. J., \& Lutzker, J. R. (2009). Population-based prevention of child maltreatment: The U.S. triple P system population trial. Prevention Science, 10, 1-12. doi:10.1007/s11121-009-0123-3.

Reed, A., Snyder, J., Staats, S., Forgatch, M. S., Degarmo, D. S., Patterson, G. R., et al. (2013). Duration and mutual entrainment of changes in parenting practices engendered by behavioral parent training targeting recently separated mothers. Journal of Family Psychology, 27, 343-354. doi:10.1037/a0032887.

Riley, A. W., Valdez, C. R., Barrueco, S., Mills, C., Beardslee, W., Sandler, I., \& Rawal, P. (2008). Development of a family-based program to reduce risk and promote resilience among families affected by maternal depression: Theoretical basis and program description. Clinical Child and Family Psychology Review, 11, 12-29. doi:10.1007/s10567-008-0030-3.

Sbarra, D. A., Law, R. W., \& Portley, R. M. (2011). Divorce and death: A meta-analysis and research agenda for clinical, social, and health psychology. Perspectives on Psychological Science, 6 , 454-474. doi:10.1177/1745691611414724.

Shay, N. L., \& Knutson, J. F. (2008). Maternal depression and trait anger as risk factors for escalated physical discipline. Child Maltreatment, 13, 39-49. doi:10.1177/1077559507310611.

Sidebotham, P., \& Golding, J. (2001). Child maltreatment in the "children of the nineties": A longitudinal study of parental risk factors. Child Abuse \& Neglect, 25, 1177-1200. doi:10.1016/ S0145-2134(01)00261-7. 
Stith, S. M., Liu, T., Davies, L. C., Boykin, E. L., Alder, M. C., Harris, J. M., et al. (2009). Risk factors in child maltreatment: A metaanalytic review of the literature. Aggression and Violent Behavior, 14, 13-29. doi:10.1016/j.avb.2006.03.006.

Strohschein, L. (2007). Challenging the presumption of diminished capacity to parent: Does divorce really change parenting practices? Family Relations, 56, 358-368. doi:10.1111/j.1741-3729. 2007.00465.x.

Turner, H. A., Finkelhor, D., \& Ormrod, R. (2007). Family structure variations in patterns and predictors of child victimization. American Journal of Orthopsychiatry, 77, 282-295. doi:10.1037/ 0002-9432.77.2.282.

Turney, K. (2011). Labored love: Examining the link between maternal depression and parenting behaviors. Social Science Research, 40, 399-415. doi:10.1016/j.ssresearch.2010.09.009.

van Eck, M., Berkhof, H., Nicolson, N., \& Sulon, J. (2005). The effects of perceived stress, traits, mood states, and stressful daily events on salivary cortisol. Psychosomatic Medicine, 58, 447-458. doi:10.1097/00006842-199609000-00007.
Weissman, A. M., Jogerst, G. J., \& Dawson, J. D. (2003). Community characteristics associated with child abuse in Iowa. Child Abuse \& Neglect, 27, 1145-1159. doi:10.1016/j.chiabu.2003.09.002.

Wilson, S., \& Durbin, C. E. (2010). Effects of paternal depression on fathers' parenting behaviors: A meta-analytic review. Clinical Psychology Review, 30, 167-180. doi:10.1016/j.cpr. 2009.10.007.

Wu, S. S., Ma, C. X., Carter, R. L., Ariet, M., Feaver, E. A., Resnick, M. B., \& Roth, J. (2004). Risk factors for infant maltreatment: A population-based study. Child Abuse \& Neglect, 28, 1253-1264. doi:10.1016/j.chiabu.2004.07.005.

Yárnoz-Yaben, S. (2015). Forgiveness, adjustment to divorce and support from the former spouse in Spain. Journal of Child and Family Studies, 24, 289-297. doi:10.1007/s10826013-9835-x.

Yárnoz-Yaben, S., Garmendia, A., \& Comino, P. (2016). Looking at the bright side: Forgiveness and subjective well-being in divorced Spanish parents. Journal of Happiness Studies, 17, 1905-1919. doi:10.1007/s10902-015-9677-x. 